\title{
Patient care accountability frameworks: the key to success for our healthcare system
}

\author{
Paul Atkinson ${ }^{1}$ (iD $\cdot$ Grant Innes $^{2}$
}

Received: 13 November 2020 / Accepted: 28 November 2020 / Published online: 4 January 2021

(c) Canadian Association of Emergency Physicians (CAEP)/ Association Canadienne de Médecine d'Urgence (ACMU) 2021

An elderly woman in a nursing home develops a fever. Her overworked nurse decides to send her to the local emergency department (ED) for timely assessment. A young man, concerned by the appearance of his wound 2 days after appendectomy is advised by his surgeon's office to go to the ED. A young woman with acute abdominal pain attends the ED but is triaged to a crowded waiting room, where she cannot lie down or get relief. An elderly woman with acute confusion waits for hours in the ambulance offload queue because the ED is full. Meanwhile, a patient with heart failure who has been treated and stabilized in the ED waits in a monitored $\mathrm{ED}$ bed $20 \mathrm{~h}$ after being "admitted" by the internal medicine team. His daughter is frustrated that he cannot get to the washroom, he is hungry and he cannot sleep (it is noisy and the lights are on). A chemotherapy patient who is feeling tired and feverish follows the guidance of her patient advice card and goes to the ED for assessment. She waits in a triage line among several others who also appear unwell.

Our "second-to-none" healthcare system is not a high performer [1]. Among 28 Organisation for Economic Cooperation and Development (OECD) countries, Canada ranks 26th on physicians per capita and for number of acute care beds. We rank 22nd of 27 for imaging capacity and have the lowest hospitalization rate among OECD countries [2]. Canadians have the worst access to same- or next-day primary care appointments and are most likely to wait over 2 months for a specialist appointment, or over 4 months for elective surgery [1, 3, 4]. Long-term care is under-resourced in many Canadian jurisdictions, leading to large numbers of alternate level of care patients occupying scarce hospital

Paul Atkinson

Paul.atkinson@dal.ca

1 Department of Emergency Medicine, Dalhousie University, Horizon Health Network, 400 University Ave, Saint John, New Brunswick, Canada

2 Department of Emergency Medicine, Cumming School of Medicine, University of Calgary, Calgary, Alberta, Canada beds [5]. Limited access to primary care, specialist care, surgical care and imaging forces Canadians to use EDs more frequently than patients in other countries, often for routine medical care [6]. But despite poor access throughout the system, EDs are expected to provide immediate or very rapid care, although most cannot. Expectations for rapid high-quality emergency care while simultaneously boarding large numbers of inpatients who cannot access hospital beds and providing safety-net care for patients who cannot access primary or specialty care has stretched ED staff and capacity beyond their limits. The result is overcrowding, adverse outcomes, suboptimal patient experience and mental health consequences for healthcare workers [7, 8].

The Canadian Association of Emergency Physicians (CAEP) defines emergency medicine [9] as a field of practice comprised by a unique set of competencies required for the timely evaluation, diagnosis, treatment and disposition of all patients with injury, illness or behavioral disorders requiring expeditious care, 24/7/365. This captures our raison d'etre but not our reality. A more accurate definition might be "all patients requiring expeditious care, as well as those who fall through the cracks and cannot access care from the appropriate service". Emergency physicians and teams are proud safety-net providers, but that net is frayed, often to the point we cannot address our core responsibility-the delivery of lifesaving emergency care.

Timely care in the right place by the right providers is a goal for every health system, but ours is failing. Patients should receive timely care from physicians and services that are trained and resourced to provide their healthcare need. Patients should not wait hours for emergency care, days for primary care, or months for a specialist appointment or imaging. Nor should they have to divert to an ED when they cannot access the 'right' care. All programs are staffed, equipped and trained for the work they do. From a patient- and system perspective, it is clear the ED is not equipped or staffed to provide inpatient care any more than surgical units are designed for psychiatric care. 
Leaving patients in the wrong place for far too long is a recipe for adverse outcomes. Worse, in an interdependent system without defined accountability, failure in one silo generates failures throughout the system. Geriatric patients blocked from long-term care slip into delirium while staring at hospital ceilings. Alternate level of care (ALC) patients filling inpatient beds compromises acute care delivery, while scores of boarded inpatients filling ED stretchers compromise emergency access, blocking seriously ill patients (and those unable to access timely primary care) in waiting rooms and ambulance hallways. So, although we have the components of a healthcare system, we lack an accountability framework, and the resulting domino effect of access failure is a root cause of poor system performance.

An accountability framework is an explicit understanding that all programs or specialties are responsible to assure access and quality care for their target populations. If we had one, an accountability framework would define accountability, establish accountability zones and implement accountability strategies. Accountability for patient care means providing timely assessment and disposition; as well as budget, space, and nursing care for program patients, and contingency plans for managing surges and queues. Accountability is further defined by time goals and quality measures. Accountability zones clarify which program is responsible for which patient, although his is generally obvious and rarely in dispute. Surgical programs should address post-op wound problems; community care should deal with stable nursing home patients and out of hours primary care; oncology teams should provide safe environments for their febrile neutropenic patients; EDs should rapidly evaluate patients with ischemic stroke; and ALC patients should not deteriorate in acute care beds [10].

Sadly, accountability usually stops at a conceptual level: i.e., "Who would be accountable in a perfect world". Although physicians and health leaders generally acknowledge the need for patient care accountability, most plead helplessness when their beds are occupied by patients who should have moved on to a downstream program. Accountability needs to extend into the real world where demand is variable and patients stress systems. Real-world accountability means program leaders must solve actual occupancy and flow problems, implement surge plans and queuing strategies, and assure care for their patients rather than leaving other services to pick up the pieces when the going gets tough. When access failures occur and patients accumulate in the wrong places, medical directors must be able to look at the accountability framework and identify which (most responsible) service needs to step up with solutions. The final critical component of an accountability framework is a set of accountability strategies that move accountability from concept to reality.
Accountability does not preclude flexibility or collaboration. All teams face resource and capacity challenges that can be overwhelming. When an inpatient service faces severe stress and ED occupancy permits, the ED should provide temporizing support, and when an ED faces profound volume stress, inpatient services can return the favor; however, EDs cannot be the daily default solution to efficiency and capacity shortfalls throughout the system. Consistent use of ED resources by any given service reflects planning and process failure by that service. EDs were designed for resuscitation, rapid diagnosis and treatment, followed by transfer to definitive inpatient or outpatient care. During the last two decades, system-wide access failures have fundamentally changed the ED from a fast-paced diagnostic and procedural unit to a quasi-inpatient ward where lengths of stay extend into days at the expense of acutely ill patients, ED providers and the ED mission. One can only imagine what might happen if inpatient services proposed boarding inpatients in operating rooms for hours or days until an appropriate bed opened up.

EDs must be allowed to care for ambulance arrivals, patients in pain and the undifferentiated acutely ill who need rapid diagnosis and treatment. No rational person could believe that EDs can compensate for shortfalls in primary care, specialty care, mental health, inpatient and long-term care. But our system is adrift and laissez-faire leadership is not providing the unbalanced force we need to overcome inertia. Widespread access failure will not fix itself, and more of the same will not drive beneficial change. Solutions lie in stronger governance, accountability frameworks and accountability strategies to get patients to the care they need.

Without a destination, any road will do, and without accountability, any performance is acceptable. It will not be easy, but with strong leadership, vision and tenacity, we can hopefully transform our second-to-none system into a top ten performer.

\section{References}

1. Barua B, Moir M. Comparing performance of universal health care countries. 2019. Fraser Institute. http://www.fraserinstitute .org. Accessed 20 Oct 2020.

2. Organisation for Economic Co-operation and Development (OECD). OECD health statistics 2019. OECD. 2019.

3. Commonwealth Fund. International profiles of healthcare systems. 2017. https://www.commonwealthfund.org/sites/default/ files/documents/__media_files_publications_fund_report_2017_ may_mossialos_intl_profiles_v5.pdf. Accessed 20 Oct 2020.

4. MacKay J, Atkinson P, Palmer E, et al. Alternate access to care: a cross sectional survey of low acuity emergency department patients. Cureus. 2017;9(6).

5. Innes G. Sorry-we're full! Access block and accountability failure in the health care system. Can J Emerg Med. 2015;17(2):171-9. 
6. Canadian Institute for Health Information. Sources of potentially avoidable emergency department visits. Ottawa, ON: CIHI. 2014. https://secure.cihi.ca/free_products/ED_Report_ForWeb_EN_ Final.pdf. Accessed 20 Oct 2020.

7. Howlett M, Doody K, Murray J, LeBlanc-Duchin D, Fraser J, Atkinson PR. Burnout in emergency department healthcare professionals is associated with coping style: a cross-sectional survey. Emerg Med J. 2015;32(9):722-7.

8. de Wit K. Burnout and depression among Canadian emergency physicians. Can J Emerg Med. 2020;22(5):559-60.
9. McEwen J, Borreman S, Caudle J, Chan T, Chochinov A, Christenson J, Currie T, Fuller B, Howlett M, Koczerginski J, Kuuskne M. Position statement on emergency medicine definitions from the Canadian association of emergency physicians. Can J Emerg Med. 2018;20(4):501-6.

10. Health Leaders Canada, 2018. Concepts related to accountability. https://youtu.be/66DRmyEUNso Accessed 16 Oct 2020. 